\title{
An Investigation of Entry Level Doctor of Physical Therapy Student Perspectives of Peer Evaluation
}

\author{
Dawn James \\ West Coast University, dawnjamespt@hotmail.com \\ Natalie Weeks-O'Neal \\ West Coast University, nweeks@westcoastuniversity.edu \\ Jennyfer Oh \\ West Coast University, jennyferohpt@gmail.com \\ Teressa Brown \\ West Coast University, tbrown@westcoastuniversity.edu
}

Follow this and additional works at: https://nsuworks.nova.edu/ijahsp

Part of the Curriculum and Instruction Commons, Educational Methods Commons, Higher Education Commons, and the Physical Therapy Commons

\section{Recommended Citation}

James D, Weeks-O'Neal N, Oh J, Brown T. An Investigation of Entry Level Doctor of Physical Therapy Student Perspectives of Peer Evaluation. The Internet Journal of Allied Health Sciences and Practice. 2019 Jan 01;17(2), Article 9.

This Manuscript is brought to you for free and open access by the College of Health Care Sciences at NSUWorks. It has been accepted for inclusion in Internet Journal of Allied Health Sciences and Practice by an authorized editor of NSUWorks. For more information, please contact nsuworks@nova.edu. 


\title{
An Investigation of Entry Level Doctor of Physical Therapy Student Perspectives of Peer Evaluation
}

\begin{abstract}
Purpose: To describe the perceptions of peer evaluation as an instructional method when used by entrylevel doctor of physical therapy (DPT) students as preparation for practical examinations within a clinically oriented course.

Methods/Description: Forty first year, entry-level doctor of physical therapy students participated in structured peer-skills checks prior to practical exams as part a clinically based course. Each student was required to observe and provide critical feedback for at least four other students as they performed simulated patient care activities. Peer-evaluators rated the students on their level of competency with the skills using a Visual Analog Scale and provided written feedback specifying areas of strength and areas needing improvement. Following the conclusion of the course, students completed a questionnaire using online survey software. The questionnaire was designed to investigate student perceptions related to skill acquisition, giving and accepting feedback, and the overall value of peer-feedback.
\end{abstract}

Results: Themes emerged regarding the value of practice and repetition, emerging reflective practice skills, emerging critical thinking and problem solving skills, and the use of peer feedback for improved performance. The value of practice and repetition was reflected in statements such as the skills checks "helped me organize my interviews...and get over my fear of the unknown." Emerging reflective practice was demonstrated by comments such as "made me self-reflect on my abilities to perform skills." The development of clinical reasoning and problem solving skills were evidenced by comments of "the skills check helped me think through what to do when things did not go as planned..." The value of feedback was reflected in comments such as "It helped me refine my skills and develop the areas that aren't as strong," "I embraced the feedback...I could work on my weaknesses."

Conclusions: Literature supports peer evaluation as an instructional tool within allied health education; however, minimal research has been completed within the profession of physical therapy education. Based on the results of this study, entry-level doctor of physical therapy students perceive peer-evaluation as an effective instructional method to assist in developing psychomotor skills necessary for patient care, as well as, affective skills necessary for reflective practice and cognitive skills related to clinical reasoning.

\section{Author Bio(s)}

Dawn James, PT, DPT is an Assistant Professor in the Doctor of Physical Therapy Program at West Coast University's Center for Graduate Studies in Los Angeles, CA. She is a Board-Certified Clinical Specialist in Pediatric Physical Therapy and maintains a pediatric clinical practice in the Los Angeles area.

Natalie Weeks-O'Neal, PT, DPT is an Assistant Professor in the Doctor of Physical Therapy Program at West Coast University in Los Angeles, CA. She is also an acute care physical therapist at Long Beach Memorial Medical Center in Long Beach, CA.

Jennyfer Oh, PT, DPT is a Teaching Assistant in the Doctor of Physical Therapy Program at West Coast University in Los Angeles, CA. She is also a Certified Strength and Conditioning Coach and full-time clinician practicing vestibular out-patient physical therapy.

Teressa Brown, PT, DPT, PhD is the Dean and Program Director of the Doctor of Physical Therapy Program at West Coast University in Los Angeles California. Her PhD is in Health Professions Education. She is also a Board Certified Clinical Specialist in Orthopedic Physical Therapy currently licensed in California. 


\section{Acknowledgements}

The authors wish to thank Dr. Kathleen Dwyer for her advice and guidance during the initial planning and development of this research work. Her encouragement and early critiques were very much appreciated. 


\title{
IIAHSP ${ }^{\mathrm{m}}$ \\ The Internet Journal of Allied Health Sciences and Practice \\ Dedicated to allied health professional practice and education \\ Vol. 17 No. 2 ISSN 1540-580X
}

\section{An Investigation of Entry-Level Doctor of Physical Therapy Student Perspectives of Peer Evaluation}

\author{
Dawn James \\ Natalie Weeks-O'Neal \\ Jennyfer Oh \\ Teressa Brown \\ West Coast University \\ United States
}

\begin{abstract}
Purpose: To describe the perceptions of peer evaluation as an instructional method when used by entry-level Doctor of Physical Therapy (DPT) students as preparation for practical examinations within a clinically oriented course. Methods: Forty (40) first-year, entry-level DPT students participated in structured peer-skills checks prior to practical exams as part a clinically based course. Each student was required to observe and provide critical feedback for at least four other students as they performed simulated patient care activities. Peer-evaluators rated the students on their level of competency with the skills using a visual analog scale and provided written feedback specifying areas of strength and areas needing improvement. Following the conclusion of the course, students completed a questionnaire using online survey software. The questionnaire was designed to investigate student perceptions related to skill acquisition, giving and accepting feedback, and the overall value of peer-feedback. Results: Themes emerged regarding the value of practice and repetition, emerging reflective practice skills, emerging critical thinking and problemsolving skills, and the use of peer feedback for improved performance. The value of practice and repetition was reflected in statements such as the skills checks "helped me organize my interviews...and get over my fear of the unknown." Emerging reflective practice was demonstrated by comments such as "made me self-reflect on my abilities to perform skills." The development of clinical reasoning and problem-solving skills were evidenced by comments of, "The skills check helped me think through what to do when things did not go as planned..." The value of feedback was reflected in comments such as, "It helped me refine my skills and develop the areas that aren't as strong," and "I embraced the feedback...I could work on my weaknesses." Conclusions: The literature supports peer evaluation as an instructional tool within allied health education, however, minimal research has been completed within the profession of physical therapy education. Based on the results of this study, entry-level DPT Students perceive peer-evaluation as an effective instructional method to assist in developing psychomotor skills necessary for patient care, as well as, affective skills necessary for reflective practice and cognitive skills related to clinical reasoning.
\end{abstract}

Keywords: peer evaluation, instructional methods, feedback, student perceptions, physical therapist education 


\section{INTRODUCTION}

Accreditation standards for entry-level doctor of physical therapy (DPT) programs require that instructional methods are effective and meet the needs of the learner and defined student outcomes. ${ }^{1}$ Peer evaluation, or peer assessment, is an instructional method currently utilized within entry-level DPT programs; however, little is known about the efficacy of this instructional method specific to student outcomes in the areas of teaching and learning, communication, and clinical reasoning. Accreditation standards also require the entry-level DPT curriculum include content and learning experiences involving teaching and learning, communication, and clinical reasoning. Faculty within entry-level programs are responsible for ensuring that learning experiences designed and implemented within their courses meet these standards and that students exhibit the skills necessary for entry-level physical therapy practice upon graduation. The purpose of this study is to examine student perception of peer evaluation as an instructional method when used as preparation for practical examinations within an entry-level DPT course.

\section{Research Question}

How do entry-level DPT students perceive peer evaluation when used as an instructional strategy within a clinically oriented course?

\section{Sub Questions}

- How do students perceive the process of being evaluated by peers?

- How do students perceive the peer evaluation process from the perspective of the evaluator?

- How do students use the peer feedback process to prepare for practical examinations?

-What do students perceive as the benefits of peer evaluation?

- What do students perceive as the drawbacks of peer evaluation?

\section{BACKGROUND}

The purpose of this qualitative descriptive study is to describe the perceptions of peer evaluation, or peer assessment, as an instructional method when used by entry-level DPT students as preparation for practical examinations within a clinically oriented physical therapy course. Peer evaluation is defined as an instructional strategy in which students analyze, assess, and comment on peer proficiency and performance. ${ }^{2}$ While some research has been completed in the area of peer evaluation in allied health and medical student education, it does not address the specific question of how peer evaluation affects the development of skills required for current entry-level practice of physical therapy across the psychomotor, cognitive, and affective domains. Physical therapy educators are required to use a "variety of effective instructional methods selected to maximize learning...chosen based on the nature of the content, the needs of the learners, and the defined expected student outcomes". ${ }^{1}$ These instructional methods should substantially contribute to the development of entry-level physical therapy skills and behaviors.

The faculty is responsible for providing content as well as the assessment of student performance across the psychomotor, cognitive, and affective domains. Additional responsibilities include instruction in the basic sciences, examination techniques, and physical therapy interventions, as well as, teaching and learning, communication, and clinical reasoning. By examining student perceptions of peer evaluation when used as an instructional method within a clinically based course, a better understanding of student needs and the effectiveness of the instructional method can be gleaned. This foundational understanding will provide insight and support for faculty making decisions regarding instructional methods for entry-level DPT courses.

Peer evaluation was built into a first-year clinically oriented course at the University of interest in the form of "peer skills checks" in order to assist students in preparing for their first practical examination experience. The peer skill checks provided students with structured opportunities to practice patient care skills while being observed and critically evaluated by their peers. All students were required to evaluate at least four other students and be evaluated four times by a peer during the process. The assumption was that both the role of evaluator and evaluee would provide benefit to the students by giving and receiving feedback across all three learning domains (cognitive, affective and psychomotor). It was hypothesized that the evaluation process would lead to improved student confidence and outcomes regarding communication skills, organization during the simulated patient interaction, and psychomotor skills required to complete examination and intervention procedures. This study sought to investigate the benefits that peer evaluation provides by examining student perceptions of the process and determining how students felt about and utilized peer feedback to prepare for a practical examination within an entry-level DPT course.

\section{LITERATURE REVIEW}

Faculty may be hesitant to use peer feedback because of concerns regarding student capabilities, negative student responses, and time constraints. ${ }^{3,4}$ However, peer evaluation is associated with numerous pedagogical benefits including enhanced active student engagement, improved quality of work, increased ability to provide feedback, improved clinical skills, and increased levels 
of confidence.5,6 It is hypothesized that peer assessment and learning can lead to the development of student responsibility for learning and in the development of metacognitive skills as students must take an active role in the learning process. 7,8

While some research has been completed in the area of peer evaluation in allied health education, current research focuses primarily on nursing students and undergraduate physical therapy students. Kim-Godwin et al studied fifty undergraduate nursing students and found that the students perceived the use of peer evaluation during the simulation to be highly effective in helping them to improve assessment, communication, critical thinking, and technical skills. ${ }^{6}$

A study of Dutch undergraduate physical therapy students found that the students did not find the act of providing peer evaluation to be a powerful element in instruction compared to the actual performance of the skills. ${ }^{9}$ However, through participation in a peer evaluation activity, the students reported positive results such as gaining knowledge of performance from a different perspective, learning about alternative performance, engaging in mirroring and modeling, and received information regarding areas of improvement. Similarly, a study conducted by Maas et al concluded that peer assessment had a positive impact on clinical performance through intended and unintended learning. ${ }^{9}$ McGarr and Clifford also studied student perceptions of peer learning and assessment among a group of undergraduate physical therapy students and graduate level education students in Ireland. ${ }^{10}$ These authors found that students perceived value in receiving feedback from peers. The researchers also reported that students felt more aware of effective teaching strategies and were better prepared for future professional roles. ${ }^{10}$

Peer-evaluation regarding the affective domain, specifically under the contexts of professionalism and career development, has also been studied in the career development of nurses and has found to assist nurses' professional development and increase collaboration with peers. ${ }^{11}$ Youdas et al studied the role of feedback in relation to professional development skills among first-year DPT students in the United States. ${ }^{12}$ Youdas et al concluded that student improvements in professional behaviors could be partially attributed to expectations for improvement and implied peer pressure to achieve. ${ }^{12}$ Youdas et al believed that Millenials' preference for working in peer partnerships, desire for immediate and positive feedback, and desire to feel respected by peers was related to the students' successes. ${ }^{12}$

Current research supports the use of peer evaluation as an instructional tool in higher education, however, due to participant age, experience in education, country of origin, variations in accreditation requirements, and the level of instruction in a graduate degree program, the results of these studies may not be transferrable to entry-level DPT education. Research involving the student perspective of peer evaluation is lacking. Additionally, current research does not address the specific question of how peer evaluation affects the development of skills required for the entry-level practice of physical therapy across the psychomotor, cognitive, and affective domains. Reflective practice is one of the hallmarks of an expert clinician. ${ }^{13}$ To help develop the skills needed for reflection, students need to develop an awareness of self and determine how a patient has been affected by their actions or how the patient has affected the situation. By providing opportunities for students to observe each other in simulated patient experiences, challenge each other's clinical reasoning, and provide critical feedback regarding performance and communication, instructors provide a frame of reference which can assist students in developing skills needed to move this reflection internally toward professional reflection used in clinical reasoning. ${ }^{13}$ This study evaluates the success of this innovative teaching strategy through the lens of student outcomes and accreditation standards.

\section{METHODS}

This qualitative study allowed for an in-depth investigation of how students perceive certain activities and instructional methods and provides physical therapy faculty with feedback to improve instruction. The method chosen for this study was a qualitative description as referenced by Sandelowski.14,15 Qualitative description research is described as a detailed description of an event or experience and typically involves a more structured interview. ${ }^{16}$ According to Neergaard et al, a qualitative description "is especially relevant in mixed method research, in questionnaire development, and in research projects aiming to gain firsthand knowledge of ...professionals' experiences with a particular topic." 16 Qualitative description is less interpretive or abstract than other forms of qualitative research, because of its theoretical and interpretive undertones and decreased reliance on pre-existing theory, it can provide invaluable information. ${ }^{14,15}$

\section{Subjects/Setting/Site}

The subjects were 40 entry-level DPT students. Because the study was specific to entry-level DPT students who participated in peer evaluation activities, purposeful sampling as described by Palinkas et al was used. ${ }^{18}$ Subjects consisted of a criterion sample of first-year DPT students who had completed practical exams in the Clinical Skills I Course at a university located in the Western United States. Fifteen is the smallest acceptable sample size for qualitative research and the most common sample size to reach saturation in qualitative research is between 20 to $30 .{ }^{19}$ Therefore, the ideal sample size to develop well-saturated findings for this study was 35 .

(c) The Internet Journal of Allied Health Sciences and Practice, 2019 
All subjects were provided with a consent form, which informed them of the rationale for the invitation to participate in the study, study procedures, risks and benefits, and their rights as subjects. Recruitment was accomplished via email invitation to the class. A total of forty (40) students were enrolled for data analysis.

\section{Data Collection}

Data collection occurred online. As the subjects were enrolled students in a course and the primary investigator was the course coordinator, an asymmetrical relationship between the researcher and the subjects is inherent. Therefore, data collection methods were chosen to ensure anonymity thus addressing any power issues and reciprocity or grading bias that may have arisen. Data gathered through this study provided the researchers with information necessary to determine whether peer-evaluation is an effective instructional strategy and a benefit to entry-level DPT students. ${ }^{2}$

\section{Data Generation}

Data were collected through a structured, online, open-ended questionnaire (Appendix A) using online survey software. This provided the subjects the ability to answer the questions anonymously and reduced bias that might have been introduced by the dual roles of the instructor/researcher. Open-ended questions allowed the subjects to provide a detailed and personal account of their perceptions of the peer-evaluation process.

\section{Data Analysis}

To gain an understanding of how the primary researcher's thoughts, feelings, and experiences would inform the analysis of the data, the first step in data analysis was to complete a reflexivity memo. ${ }^{2}$ Reflexivity allows for a transparent process and can help the researcher explore both implicit and explicit concepts that might influence the analytic process. ${ }^{20}$ The purpose of the reflexivity memo was to inform the researcher of specific biases and to reveal preconceived assumptions regarding the subject. ${ }^{20}$ Following the reflexivity memo, the initial analysis consisted of a reading through the completed observation records and surveys followed by an analytic memo written to capture a general idea and understanding of first impressions. Analytic memos or "node memos" were used throughout the data analysis process to organize and clarify the process. ${ }^{21}$

Coding was initially completed using in vivo coding as described by Marshall and Rossman. ${ }^{21}$ This process involved identifying exact words or phrases that stood out to the researchers upon first reading. As the surveys and observations were read in more depth, categories were developed and defined using the data analysis spiral described by Creswell and Poth. ${ }^{2}$ These categories were reviewed, and a coding book was developed. Final major categories were developed using coding strategies described by Creswell and Poth and Marshall and Rossman. 2,21 Through the systematic coding process, themes were identified and considered in relation to the study questions (Table 1). This allowed the investigators to compare student responses, draw inferences to help understand and explain the complexity and richness of the findings, and answer the study questions related to peer-evaluation as an instructional process. Qualitative description, content analysis, and descriptive statistics were used for data analysis.

Table 1. Example of Coding Process and Theme Development

\begin{tabular}{|l|l|l|}
\hline In vivo coding & Associated Categories & Theme \\
\hline $\begin{array}{l}\text { Comfortable; practice; confident; } \\
\text { repetition; provided necessary } \\
\text { practice makes perfect }\end{array}$ & Confidence; Practice; Repetition & Value of Practice and Repetition \\
\hline $\begin{array}{l}\text { Comparing; think through what to do: } \\
\begin{array}{l}\text { Think on my feet; changed what } \\
\text { needed to be changed; analyze my } \\
\text { performance; more aware; observing } \\
\text { others; identifying weaknesses }\end{array}\end{array}$ & $\begin{array}{l}\text { Reflection; Self-reflection; Improve } \\
\text { skills }\end{array}$ & Emerging Reflective Practice \\
\hline $\begin{array}{l}\text { Varied scenarios challenged critical } \\
\text { thinking; critical eye; practice clinical } \\
\text { reasoning; }\end{array}$ & Problem Solving; Clinical Reasoning & Development of Clinical Reasoning and \\
\hline $\begin{array}{l}\text { Seeing others; constructive feedback; } \\
\text { learn from each other; providing } \\
\text { feedback; giving feedback; providing } \\
\text { input; constructive; receptive; observing } \\
\text { others }\end{array}$ & Feedback & Problem-Solving Skills \\
\hline
\end{tabular}

(c) The Internet Journal of Allied Health Sciences and Practice, 2019 
Once themes were developed, a secondary analysis addressing specific sub-questions was completed. The secondary analysis used focused coding based on the context of the sub-question. Categories related to sub-questions were identified (perception of peer evaluation process, use of feedback, and perceived benefits). Responses were read in depth and assigned to the defined categories (Figure 1). Once assigned to a category, the responses were analyzed allowing the researchers to categorize related responses, draw conclusions, and answer the sub-questions.

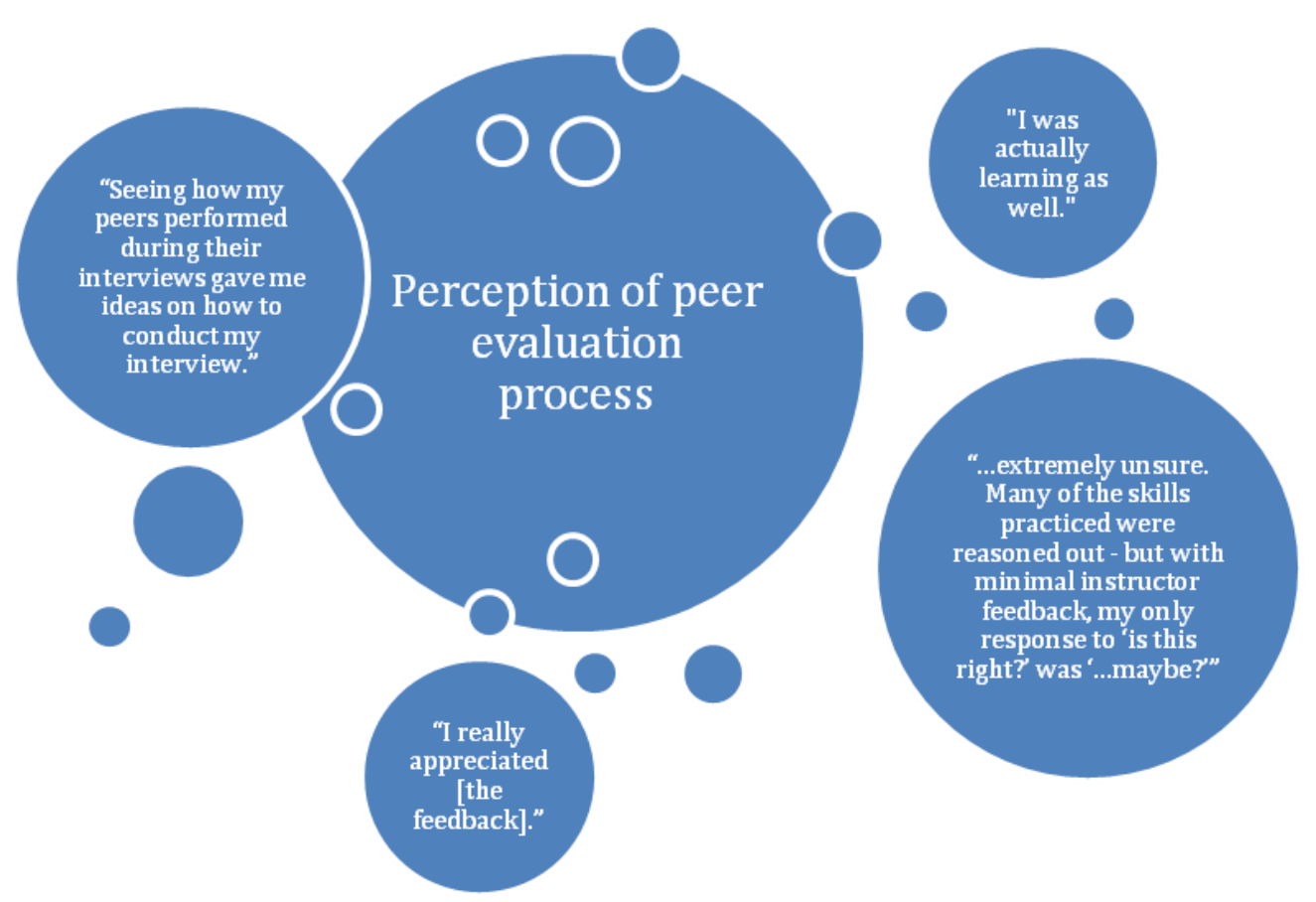

Figure 1. Secondary Coding Process

\section{Scientific Rigor}

Scientific rigor, or trustworthiness, was established by ensuring credibility, transferability, dependability, and confirmability. ${ }^{22}$ Credibility refers to the confidence of the findings. ${ }^{23}$ Credibility was established using existing study protocols and triangulation of data. Data from the on-line survey was reviewed and coded by multiple reviewers to establish inter-rater reliability. Completion of an initial reflexivity memo and analytic memos throughout the data analysis process minimized individual biases that may have influenced the analysis. ${ }^{2}$ Transferability refers to how applicable the findings are to other contexts. ${ }^{23}$ To ensure transferability, the information was presented in detail and from multiple perspectives as described by Creswell and Poth. ${ }^{2}$ Use of a codebook and detailed documentation of the methods used to complete the study assisted in establishing dependability. Confirmability, or objectivity, was established using multiple tools, data collection approaches, and multiple reviewers thus reducing bias.2,21,22

\section{Ethical Issues}

Protection of Human Subjects

This study was submitted to the West Coast University Internal Review Board (IRB) for approval and to ensure that the rights and welfare of the student participants were protected. As this research is educational in nature and involved the study of current educational practice within an existing course and anonymous surveys to gather data, it qualified for exempt human subject status. As the primary investigator also holds a role of instructor, the surveys were completed anonymously via on-line survey software after completion of the course to remove any bias and assist in developing trust. All students were provided with a consent form as part of the survey which outlined the benefits of participation.

\section{RESULTS}

A total of 27 first-year DPT students participated in the study. Upon analysis, themes emerged regarding the value of practice and repetition, emerging reflective practice skills, emerging critical thinking and problem-solving skills, and the use of peer feedback for improved performance. 


\section{Value of Practice and Repetition}

Research has shown that motor skill learning can be enhanced when practice is individualized to the learner's needs and results in better retention of psychomotor skills. ${ }^{24}$ By giving the learners control over the structure of practice through the peer evaluation process, students designed practice sessions that provided the insight into areas needing further improvement and sessions purposefully tailored to address a variety of potential clinical scenarios.

Students found value in practice and repetition that the peer evaluation process offered. This was reflected in statements such as the skills checks

"helped me organize my interviews...and get over my fear of the unknown" and "required us to practice and run through different clinical situations, which was really helpful. We knew what we needed to improve on, and for me that was practicing with assistive devices (ADs) and catheters, intravenous line (IV) poles, etc."

\section{Emerging Reflective Practice}

Reflective practice has been identified as an essential competency for healthcare professionals and should be developed throughout the educational career of student physical therapists. Reflective practice can be developed when students are made aware of a need. ${ }^{24}$ Through the process of peer evaluation, students were encouraged to identify areas of strength as well as areas in need of improvement.

Emerging reflective practice was demonstrated by student comments such as

"[s]eeing other people's methods and comparing it with my own made me improve," "being able to observe others helps me recognize my own strengths and weaknesses," and "[b]eing critical of others made me self-reflect on my abilities to perform skills."

\section{Development of Clinical Reasoning and Problem-Solving Skills}

Clinical reasoning is a complex, ongoing, process that utilizes narrative thinking to make determinations regarding patient care. 25,26 Due to the autonomous nature of physical therapy practice, clinical reasoning skills are imperative for the student physical therapist to develop..$^{26}$

The development of clinical reasoning and problem-solving skills were evidenced by student comments such as

"[we] came across varied scenarios challenging critical thinking skills," "the skills check helped me think through what to do when things did not go as planned," and "[other students] would throw random scenarios at me and I had to think on my feet."

\section{Value of Feedback}

Peer evaluations were structured so that students provided feedback to each other for improving performance during the practical examinations. By providing each other external feedback, students were able to develop a performance standard for themselves. Peer feedback served to provide missing information needed to develop this standard and improve their overall skill level. ${ }^{9}$

Students found value in receiving feedback from peers. The value of feedback was reflected in comments such as

"It helped me refine my skills and develop the areas that aren't as strong," and "l embraced the feedback, and used it to make some changes and continued to practice so I could work on my weaknesses."

\section{Sub Questions:}

\section{How did students perceive the process of being evaluated by peers?}

Students reported being open to receiving constructive feedback from the peer evaluation process. Openness was evidenced by comments such as

"I embraced the feedback" and "I really appreciated [the feedback]."

No students reported negative perceptions of the peer evaluation process. 
How did students perceive the peer evaluation process from the perspective of the evaluator? Most students found value in the role of evaluator. One student reported,

"Seeing how my peers performed during their interviews gave me ideas on how to conduct my interview."

Another student reported,

"I felt good because I was actually learning as well."

However, one student felt

"...extremely unsure. Many of the skills practiced were reasoned out - but with minimal instructor feedback, my only response to 'is this right?' was '... maybe?'” Another student felt "slightly insecure about providing feedback since I have not had an abundant amount of clinic experience; however, I thought looking to provide feedback helped my critical eye."

How do students use the peer feedback process to prepare for practical examinations?

Students reported using the information gathered from peer evaluation to "correct flaws," "make changes" to certain skills, and "refine performance" before the practical exam. One student reported trying

"to analyze my performance from [the peer evaluator's] perspective during subsequent practice sessions."

What do students perceive as the benefits of peer evaluation?

Perceived benefits included increased confidence, active learning and observation skills, personal communication skills, and the ability to critically analyze patient care activities. One student stated,

"It is really good practice for a clinic setting and will make us better PTs."

What do students perceive as the drawbacks or negatives of peer evaluation?

While several students reported no drawbacks, others reported having some difficulty navigating the peer evaluations with minimal faculty support and felt that student input was "inferior to that of professors."

\section{DISCUSSION}

Overall, students expressed positive feelings regarding the use of peer evaluation with a clinically based course. Students reported improved confidence in their psychomotor skills, improved communication skills, and referenced improved development of clinical reasoning and problem-solving skills. Improvements were also noted in the development of affective skills including increased confidence, improved communication skills, and self-reflection skills. Students used the information gained from peer feedback to prepare for simulated patient activities and establish an overall flow of the patient care interaction. While students felt that faculty input was superior to that of peers, they found value in peer feedback received during this experience and used the feedback to better self-assess and critically reflect on their performance. A primary limitation of this study is that it focused solely on the students' perceptions of the peer-evaluation process and there were no objective measurements to demonstrate actual improvement in performance. This will be examined in future peer evaluation sessions. While reflexivity and triangulation were used throughout the data collection and analysis process, it is important to note that qualitative description can be more susceptible to researcher bias and the researcher's dual roles of investigator and instructor may have introduced bias.

\section{CONCLUSION}

Based on the results of this study, peer evaluation appears to be a beneficial instructional tool within entry-level DPT programs. Four key themes we identified regarding the use of peer evaluation as an instructional tool within a clinically oriented physical therapy course. While DPT students found the practice and repetition associated with peer skills checks to be helpful in gaining both psychomotor skills and confidence, they found peer feedback valuable for improving performance and developing critical thinking and clinical reasoning skills.

\section{CLINICAL RELEVANCE}

Literature supports peer evaluation as an instructional tool within allied health education, however, minimal research has been completed within the field of physical therapy education, and no studies to date have been completed with entry-level DPT students. Based on the results of this study, entry-level DPT students perceive peer-evaluation as an effective instructional 
method to assist in developing psychomotor skills necessary for patient care, as well as, affective skills necessary for reflective practice and cognitive skills related to clinical reasoning.

\section{REFERENCES}

1. Commission on Accreditation of Physical Therapy Education (2015). Standards and required elements for accreditation of physical therapist education programs. Alexandria, VA: American Physical Therapy Association, 2015.

2. Creswell J, Poth CN. Qualitative Inquiry And Research Design, $4^{\text {th }}$ Edition. Thousand Oaks, Calif.: Sage; 2018.

3. Rubin R. The Academic Journal Review Process as a Framework for Student Developmental Peer Feedback. $J$ Management Educ. 2006;30(2):378-98. doi:10.1177/1052562905277185.

4. Liu N, Carless D. Peer feedback: the learning element of peer assessment. Teaching in Higher Educ. 2006;11(3):27990. doi:10.1080/13562510600680582

5. Brewer E. Successful Techniques for Using Human Patient Simulation in Nursing Education. J Nurs Scholarsh. 2011:43(3):311-7. doi:10.1111/j.1547-5069.2011.01405.x. [PMID: 21884377]

6. Kim-Godwin Y, Livsey K, Ezzell D, Highsmith C, Winslow H, Aikman A. Students Like Peer Evaluation during Home Visit Simulation Experiences. Clin Simul Nurs. 2013;9(11):e535-42. doi:10.1016/j.ecns.2012.06.002.

7. Lydia Wen M, Tsai $\mathrm{C}$, Chang $\mathrm{C}$. Attitudes towards peer assessment: a comparison of the perspectives of pre-service and in-service teachers. Innovations in Education and Teaching International. 2006;43(1):83-92. doi:10.1080/14703290500467640.

8. van Hattum-Janssen N, Maria Lourenço J. Explicitness of criteria in peer assessment processes for first-year engineering students. European J Engineering Educ. 2006;31(6):683-91. doi:10.1080/03043790600911779.

9. Maas MJ, Sluijsmans D, van der Wees P, Heerkens Y, Nijhuis-van der Sanden M, van der Vleuten CP. Why peer assessment helps to improve clinical performance in undergraduate physical therapy education: a mixed methods design. BMC Med Educ. 2014;14(1):117. [PMID: 24928420]

10. McGarr $O$, Clifford AM. Just enough to make you take it seriously': exploring students' attitudes towards peer assessment. Higher Educ. 2013;65(6):677-93. doi: 10.1007/s10734-012-9570-z

11. Vuorinen R, Tarkka MT, Meretoja R. Peer evaluation in nurses' professional development: a pilot study to investigate the issues. J Clin Nurs. 2000;9(2):273-81. doi:10.1002/ase.1356 [PMID: 11111619]

12. Youdas JW, Krause DA, Hellyer NJ, Rindflesch AB, Hollman JH. Use of individual feedback during human gross anatomy course for enhancing professional behaviors in doctor of physical therapy students. Anat Sci Educ. 2013;6(5):324-31. doi:10.1002/ase.1356. [PMID: 23509010]

13. Wainwright SF, Shepard KF, Harman LB, Stephens J. Novice and Experienced Physical Therapist Clinicians: A Comparison of How Reflection Is Used to Inform the Clinical Decision-Making Process. Phys Ther. 2010;90(1):75-88. doi:10.2522/ptj.20090077. [PMID: 19926680]

14. Sandelowski M. Whatever happened to qualitative description? Res Nurs Health. 2000;23(4):334-40. doi:10.1002/1098-240x(200008)23:4<334::aid-nur9>3.0.co;2-g. [PMID: 10940958]

15. Sandelowski M. What's in a name? Qualitative description revisited. Res Nurs Health. 2010 Feb;33(1):77-84. doi:10.1002/nur.20362. [PMID: 20014004]

16. Neergaard MA, Olesen F, Andersen RS, Sondergaard J. Qualitative description - the poor cousin of health research? BMC Med Res Methodol. 2009;9(1):52. doi:10.1186/1471-2288-9-52. [PMID:19607668]

17. Plack M, Driscoll M. Teaching And Learning In Physical Therapy; Thorofare, NJ: Slack, Inc.; 2011

18. Palinkas L, Horwitz S, Green C, Wisdom J, Duan N, Hoagwood K. Purposeful Sampling for Qualitative Data Collection and Analysis in Mixed Method Implementation Research. Admin Policy Ment Health. 2015;42(5):533-44. doi:10.1007/s10488-013-0528-y. [PMID: 24193818]

19. Mason, M. Sample size and saturation in $\mathrm{PhD}$ studies using qualitative interviews. In Forum qualitative Sozialforschung/Forum: qualitative social research. 2010;11(3).

20. Engward $\mathrm{H}$, Davis $\mathrm{G}$. Being reflexive in qualitative grounded theory: discussion and application of a model of reflexivity. J Adv Nurs. 2015;71(7):1530-8. doi:10.1111/jan.12653. [PMID: 25825257]

21. Marshall C, Rossman G. Designing Qualitative Research. Thousand Oaks, California: SAGE; 2016.

22. Shenton A. Strategies for ensuring trustworthiness in qualitative research projects. Education for Information. 2004;22(2):63-75. doi:10.3233/efi-2004-22201.

23. Wulf G. Self-controlled practice enhances motor learning: implications for physiotherapy. Physiotherapy. 2007;93(2):96-101. doi:10.1016/j.physio.2006.08.005.

24. Lincoln YS, Guba EG. Naturalistic Inquiry. Thousand Oak, CA: SAGE; 1985. 
25. Mann K, Gordon J, MacLeod A. Reflection and reflective practice in health professions education: a systematic review. Adv Health Sci Educ Theory Pract. 2009;14(4):595-621. doi:10.1007/s10459-007-9090-2. [PMID: 18034364]

26. Baker SE, Painter EE, Morgan BC, Kaus AL, Peterson EJ, et al. Systematic Clinical Reasoning in Physical Therapy (SCRIPT): Tool for the Purposeful Practice of Clinical Reasoning in Orthopedic Manual Physical Therapy. Phys Ther. 2017;97(1):61-70. doi:10.2522/ptj.20150482. [PMID: 27470978] 
Appendix A: Survey Questions

An Investigation Of Entry-Level Physical Therapy Student Perspectives Of Peer Evaluation: A Qualitative Study

1. How did the peer skills checks prepare you for taking your practical exam?

2. How did you feel providing feedback to your peers?

3. How do you believe your peers accepted your feedback?

4. How did it feel to receive critical feedback from your peers?

5. How did you use the peer feedback?

6. What, if any, skills did you gain from being a peer evaluator?

7. How did you feel providing critical feedback to your peers?

8. How did you use the feedback provided to you?

9. What did you find most helpful about the peer skills check process?

10. What did you find least helpful about the peer skills checklist process? 